\section{Conflitos e impasses da judicialização na obtenção de medicamentos: as decisões de 1a instância nas ações individuais contra o Estado do Rio de Janeiro, Brasil, em 2005}

\author{
Conflicts and impasses in the judicialization of the \\ supply of medicines: circuit court rulings on \\ claims brought against the State of \\ Rio de Janeiro, Brazil, in 2005
}

\author{
1 European University \\ Institute, Firenze, Italia. \\ 2 Escola Nacional de Saúde \\ Pública Sergio Arouca, \\ Fundação Oswaldo Cruz, \\ Rio de Janeiro, Brasil. \\ Correspondência \\ D. C. L. Borges \\ European University \\ Institute. \\ Via Boccaccio 121, Firenze, \\ FI, 50133, Italia. \\ danielle.borges@eui.eu
}

\begin{abstract}
Based on an analysis of individual claims for provision of medicines brought by users of the Unified National Health System (SUS) against the State of Rio de Janeiro, Brazil, in the year 2005, this study aims to discuss the action and behavior of the court system in ruling on these suits. The study adopted a semi-qualitative exploratory documental research design, analyzing key aspects related to the claims, such as type of medication claimed by the plaintiff, wording of the court rulings, and the key elements used by judges in trying the cases. According to the analysis of the lawsuits and the concepts of judicialization and official standardization of medicines, the study concludes that when ruling on the provision of medicines, the court system grants the claims as submitted without considering the standardization of medicines adopted by the Ministry of Health, thus exercising excessive court intervention in health policy.
\end{abstract}

Pharmaceutical Preparations; Judicial Power; Health Policy; Single Health System
Danielle da Costa Leite Borges 1 Maria Alicia Dominguez Ugá 2

\section{Introdução}

O crescente número de ações judiciais propostas por usuários do Sistema Único de Saúde (SUS) para garantir o fornecimento de medicamentos tem sido motivo de preocupação para gestores de saúde em todos os níveis federativos. Exemplo disso é o fato de que, segundo dados da Secretaria de Saúde e Defesa Civil do Estado do Rio de Janeiro, entre 2001 e 2005, o número de ações aumentou aproximadamente $350 \%$ nessa Unidade da Federação.

As ações judiciais para fornecimento de medicamentos começaram a surgir nos tribunais após a promulgação da Constituição Federal de 1988, a qual elevou o direito à saúde ao patamar de direito fundamental. No início eram processos pleiteando medicamentos para o tratamento de HIV/AIDS que predominavam, contudo, após 1999, houve redução nos pedidos sobre tais medicamentos, surgindo outras condições patológicas dominantes 1 .

O crescimento do número de ações judiciais, associado ao fato de que as decisões são predominantemente favoráveis aos autores, vem gerando problemas para o sistema de saúde como um todo, já que algumas decisões acabam comprometendo gravemente o orçamento para a saúde, em razão do elevado preço de alguns medicamentos pleiteados, que, em muitos casos, não se encontram nos elencos oficiais da regula- 
mentação da assistência farmacêutica no âmbito do SUS.

A atuação do Poder Judiciário nesses casos acaba interferindo na política de saúde planejada pelo Poder Executivo, pois escolhas originalmente políticas e de competência dos gestores de saúde acabam sendo tomadas na esfera judicial 2 . O envolvimento do Poder Judiciário na esfera política, denominado pela doutrina de judicialização, é um fenômeno observado nas democracias contemporâneas, especialmente nos países em que o Poder Judiciário realiza o controle de constitucionalidade das leis ${ }^{3}$. Recentemente, as decisões judiciais nas ações para fornecimento de medicamentos também foram estudadas como uma forma de interferência do Poder Judiciário na política de saúde. Entretanto, essa forma de intervenção judicial é diferente da tradicionalmente estudada ${ }^{4}$. As referidas decisões judiciais indicam um novo formato de judicialização no qual o Poder Judiciário se sobrepõe ao Poder Executivo na escolha de fornecer este ou aquele medicamento, sob o fundamento de assegurar o direito à saúde 5 . E é nesse formato de judicialização que se situa o caso das ações judiciais estudadas neste artigo, no qual cidadãos buscam individualmente e por meio de procedimentos judiciais comuns a efetivação de interesses relacionados ao direito social à saúde não efetivados na esfera executiva 6 .

Ocorre, porém, que esse tipo de conflito judicial se apresenta de forma diversa daqueles que o Poder Judiciário sempre esteve acostumado a julgar, nos quais estão em jogo bens particulares, e a decisão por adjudicar os bens em conflito a uma das partes afetará apenas aqueles indivíduos envolvidos na relação jurídica. No caso das ações judiciais individuais movidas por usuários do SUS para fornecimento de medicamentos estão em jogo bens providos pelo Estado com recursos públicos e, portanto, a decisão sobre a adjudicação do bem - no caso, o medicamento - afetará, ainda que indiretamente, toda a coletividade.

Dessa forma, no caso de soluções que envolvam recursos públicos e políticas sociais, torna-se necessária a adoção de critérios racionais e uma análise de cada hipótese posta, não se podendo adotar uma única solução para todas as situações nas quais se requer o fornecimento de medicamentos 7 . Ressalte-se que a decisão de dispensar certo tipo de medicamento pelo Estado envolve critérios técnicos, nos quais se pretende garantir o acesso da população a produtos seguros, eficazes e de qualidade, e ao menor custo possível ${ }^{8}$. Desse modo, a integralidade da assistência à saúde, que inclui a assistência farmacêutica, sob esse ponto de vista, não é um conceito que admite toda e qualquer terapêutica existente ou demandada por um paciente ou profissional de saúde. Há que se ter critérios técnicos, atualizados cientificamente, para embasar a incorporação desta ou daquela tecnologia, desta ou daquela terapêutica ou medicamento 9 .

Portanto, da mesma maneira, quando decisões sobre o fornecimento de medicamentos são tomadas na esfera judicial também se faz necessária a utilização de critérios por parte do juiz, que, por não possuir expertise no tema, deve buscar, além dos fundamentos legais aplicáveis ao caso, o uso de critérios que levem em consideração a política de medicamentos planejada pelo Ministério da Saúde e demais órgãos responsáveis em níveis estadual e municipal, encarregados da seleção de medicamentos, a qual é feita por meio de listas oficiais veiculadas em normas específicas ou programas de assistência farmacêutica 10 .

Assim sendo, este artigo se propõe a discutir, com base na análise das ações judiciais individuais para fornecimento de medicamentos propostas por usuários do SUS contra o Estado do Rio de Janeiro no ano de 2005, a atuação do Poder Judiciário de primeira instância no julgamento deste tipo de processo judicial, visando especialmente a verificar se as decisões tomadas pelos juízes de primeira instância refletem a regulamentação da assistência farmacêutica no SUS. Tal análise considerará aspectos quantitativos e qualitativos, e pretende contribuir para uma melhor compreensão dos critérios que podem ser adotados pelo Poder Judiciário no julgamento de ações judiciais que envolvem o fornecimento de medicamentos.

\section{Métodos}

Esta pesquisa corresponde a um estudo documental exploratório, de caráter quali-quantitativo. Foram analisadas as sentenças proferidas em primeira instância até dezembro de 2006. Das 2.245 ações judiciais identificadas no ano de 2005, 2.062 processos já tinham sentença proferida em dezembro de 2006, momento em que se deu início à análise dos dados.

A relação de ações judiciais foi inicialmente obtida junto à Secretaria de Saúde e Defesa Civil do Estado do Rio de Janeiro em agosto de 2006, submetendo-se, posteriormente, esta relação à Divisão de Sistemas Judiciais e Extrajudiciais (DSJE) do Tribunal de Justiça do Estado do Rio de Janeiro para validação dos dados. A DJSE, além de validar os dados, consolidou as informações, incluindo, para cada processo identificado, o seu número, o nome do autor da ação, o tipo de ação 
proposta, o tipo de sentença judicial proferida e a data da sentença.

A identificação dos processos por seus números de registro no Tribunal de Justiça permite que as informações a eles referentes sejam consultadas usando-se o endereço eletrônico (http:// www.tj.rj.gov.br). Uma vez que nem todos os processos pesquisados eletronicamente continham os dados referentes aos medicamentos pleiteados nas ações, o universo da pesquisa ficou finalmente restrito àqueles processos nos quais foi possível identificar o medicamento solicitado.

Destaque-se que muitos dos medicamentos identificados estavam descritos por seus nomes comerciais. Portanto, nesses casos, procedeu-se à obtenção do nome do fármaco ou da associação medicamentosa componente do produto por meio do endereço eletrônico (http://www. genericos.med.br/).

Para fins da seleção oficial do elenco de medicamentos contidos na regulamentação da assistência farmacêutica no âmbito do SUS considerou-se o elenco identificado por Pontes Junior 11, que comporta 427 fármacos e contém produtos incluídos nos Programas de Assistência Farmacêutica do Ministério da Saúde e na Relação Nacional de Medicamentos Essenciais (RENAME) de 2002 12, lista em vigor no ano de 2005, que corresponde ao ano de propositura das ações judiciais objeto de nossa análise.

Com relação à análise das decisões judiciais, optou-se por dividi-la em dois aspectos, sendo o primeiro referente ao teor das decisões quanto à procedência do pedido do autor, e, o segundo, ao fundamento da decisão judicial, ou seja, as argumentações mais freqüentes dos juízes para chegarem à procedência ou improcedência do pedido.

\section{Resultados}

Com base nos dados fornecidos foram identificadas 2.245 ações judiciais propostas contra o Estado do Rio de Janeiro no ano de 2005, no Fórum Central da Comarca da Capital do Estado do Rio de Janeiro, tendo por objeto o fornecimento de medicamentos. Destaque-se que, em alguns casos, as ações são propostas não só contra o estado, mas também contra o município onde reside o autor da ação. Deve-se ressaltar que em algumas ações também são pleiteados outros itens além de medicamentos, tais como alimentos, camas hospitalares, cadeiras de rodas, luvas descartáveis, seringas, sondas, fraldas descartáveis, aparelhos para medir glicose, entre outros.

Os autores das ações são indivíduos que buscam ter garantido o fornecimento de determina- do medicamento, que alegam não lhes ter sido entregue pelo órgão do Poder Executivo responsável pelas ações de saúde naquela localidade. Normalmente os pedidos contêm uma providência em caráter de urgência (liminar ou pedido de antecipação de tutela) para que o medicamento pleiteado seja fornecido desde logo, não havendo necessidade, para o deferimento deste pedido, que o juiz consulte um órgão técnico ou perito médico.

Dessa forma, com relação ao teor das decisões, partindo-se do universo final de 2.062 ações com sentenças proferidas até dezembro de 2006, verificou-se que em 1.829 casos (89\%) os pedidos foram julgados totalmente procedentes, com sentenças favoráveis aos autores das ações, sendo os medicamentos pleiteados concedidos pelo juiz nos exatos termos do requerido pelo usuário. Em 153 processos (7\% dos casos), os pedidos foram julgados parcialmente procedentes, havendo concessão apenas de parte do requerido. Esses casos referem-se a pedidos nos quais o autor pleiteava outros itens além de medicamentos, tais como camas hospitalares, cadeiras de rodas, luvas descartáveis, seringas, sondas, fraldas descartáveis e aparelhos para medir glicose, sendo que o deferimento pelo juiz se deu apenas em relação aos medicamentos. Em 1\% dos casos o estado e/ou município réu da ação reconheceram que os medicamentos solicitados eram devidos aos autores das ações. Os restantes 3\% dos casos se referem a situações em que o juiz não chegou a decidir sobre o pedido de medicamento em razão de falecimento do autor, desistência da ação, abandono do processo ou interrupção no uso do medicamento pleiteado.

Observa-se, portanto, que não existem casos em que houve o indeferimento do pedido do autor, o que indica que o Poder Judiciário tem se manifestado sempre em favor do usuário quando se trata de solicitações sobre medicamentos, independentemente de ser aquele medicamento padronizado pelo Ministério da Saúde.

No que se refere ao fundamento das decisões proferidas e às argumentações mais freqüentes utilizadas pelos magistrados, observamos que todas as decisões estão fundamentadas no Artigo 196 da Constituição Federal e na Lei no . 8.080/90, com argumentações no sentido de que é um direito constitucional do cidadão receber do Estado ações e serviços de saúde, incluindo-se nele o fornecimento de medicamentos.

Ainda de acordo com as decisões, os entes federativos são solidários no dever de fornecer medicamentos aos cidadãos e, ao decidir neste sentido, a descentralização - um dos princípios do SUS e um dos eixos da Política Nacional de Medicamentos - não é reconhecida pelo Poder Judiciário, uma vez que todos os entes federa- 
tivos contra os quais foi proposta a ação judicial passam a ser igualmente responsáveis por qualquer medicamento pleiteado, seja ele da assistência básica, estratégico ou excepcional 13 . De acordo com a Súmula no ${ }^{\circ} 65$ do Tribunal de Justiça do Estado do Rio de Janeiro: "Deriva-se dos mandamentos dos Artigos 6o e 196 da Constituição Federal de 1988 e da Lei $n^{\circ}$. 8.080/90, a responsabilidade solidária da União, Estados e Municípios, garantindo o fundamental direito à saúde e conseqüente antecipação da respectiva tutelada" 14 .

Todavia, o que chama atenção nas decisões é que não fazem referência à questão da seleção de medicamentos ou às próprias listas ou programas oficiais, apesar de grande parte dos processos versarem sobre medicamentos não incluídos nestas listas, como será visto adiante. Na verdade, caso os magistrados levassem em consideração em suas decisões a regulamentação da assistência farmacêutica no SUS e concedessem solicitações apenas referentes a itens previstos em tais listas ou programas, muitos dos pedidos deveriam ser indeferidos.

No que se refere aos medicamentos, identificou-se aqueles pleiteados em 704 processos, tendo o universo final da pesquisa, no que se refere aos medicamentos, ficado restrito a este número. Nos 704 processos pesquisados foram identificados 334 produtos, entre fármacos e associações medicamentosas (Tabela 1), estando incluídos medicamentos excepcionais, estratégicos e da atenção básica. De acordo com o Ministério da Saúde, os medicamentos denominados excepcionais são destinados ao tratamento de doenças específicas, tais como Gaucher, Parkinson, Alzheimer, hepatites B e C, pacientes renais crônicos, transplantados, portadores de asma grave, anemia, dentre outras. Os medicamentos estratégicos são aqueles utilizados para tratamento das doenças de perfil endêmico, cujo controle e tratamento tenham protocolo e normas estabelecidas e que tenham impacto sócio-econômico. Entre esses programas podemos citar tuberculose, hanseníase, endemias focais, DST/AIDS, e sangue e hemoderivados. Já os medicamentos da atenção básica são aqueles destinados ao tratamento de agravos no nível primário de atenção, incluindo-se aí os medicamentos essenciais para a área de saúde mental 15 .

Nessas condições, dos 334 fármacos e associações medicamentosas pleiteados, 175 (52\%) estão padronizados pelo Ministério da Saúde, fazendo parte de programas específicos ou listados na RENAME ou em Portarias. Os restantes 159 produtos identificados (48\%) não estão listados nas normas anteriormente mencionadas, não fazendo parte, portanto, do elenco oficial de medicamentos. Destaque-se que como estados e municípios elaboram suas listas respeitando as normas do Ministério da Saúde que definem os elencos oficiais, os produtos tampouco constam em listas elaboradas nestes níveis da federação.

A Tabela 1 relaciona os medicamentos pleiteados, não padronizados, mas deferidos nas ações.

\section{Discussão dos resultados}

Os dados obtidos indicam duas situações distintas: (1) falta de adoção de critérios pelo Poder Judiciário na questão do fornecimento de medicamentos; e (2) falha do competente órgão do Poder Executivo Estadual na efetivação da assistência farmacêutica, especialmente na dispensação de medicamentos.

Iniciando-se pela análise da primeira situação, os dados mostram que os juízes de primeira instância não consideram a seleção oficial em matéria de medicamentos ao decidirem ações judiciais envolvendo o fornecimento de medicamentos, que sequer é mencionada nas decisões judiciais tomadas. Resulta daí que mesmo produtos não listados oficialmente acabam por ser dispensados à população. Atuando dessa maneira, o Poder Judiciário acaba intervindo excessivamente na política de saúde planejada pelo Poder Executivo, o que representa, como já mencionado antes, uma forma de judicialização da política de saúde 16 .

Ainda que se reconheça a legitimidade do Poder Judiciário para intervenção em decisões da administração e do Poder Legislativo 17, certos limites são necessários a tal intervenção, sob pena de ocorrer violação do princípio da separação de poderes 18 , já que decisões sobre o fornecimento de medicamentos são verdadeiras decisões sobre alocação de recursos, com teor nitidamente discricionário e político e, portanto, tocam originalmente ao Poder Legislativo e ao Poder Executivo.

Acrescente-se, ainda, que o fato de o direito à saúde estar garantido constitucionalmente $\mathrm{e}$ de o Brasil ter feito a opção por um sistema de saúde público e universal não significa que todos os serviços, tratamentos e medicamentos existentes no mercado devam ser disponibilizados pelo sistema. Por isso é necessária a prévia fixação dos serviços e produtos disponibilizados à população pelo sistema de saúde, a fim de se delimitar aquilo que pode ser exigido judicialmente do Estado 19

Portanto, não basta aos magistrados recorrerem tão somente ao fundamento constitucional do direito à saúde (Artigo 196 da Constituição) ou à Lei $n^{\circ}$. 8.080/90 para decidirem questões sobre 
Produtos identificados nas ações judiciais e sua conformidade às listas oficiais do Ministério da Saúde, levando-se em consideração os medicamentos e produtos não terapêuticos identificados em programas oficiais e na Relação Nacional de Medicamentos Essenciais (RENAME) de 200212 (total: 334 produtos).

\begin{tabular}{|c|c|c|c|c|c|}
\hline Produtos & Padronizado & Produtos & Padronizado & Produtos & Padronizado \\
\hline Acarbose & Não & Cloridrato de oxibutina & Não & Letrozol & Não \\
\hline Aceclofenaco & Não & Cloridrato de betaxolol & Não & Levomepromazina & Não \\
\hline Ácido ascórbico + arginina & Não & Cloridrato de ciclobenzaprina & Não & Lidocaína + prilocaína & Não \\
\hline Ácido gama linolênico & Não & Cloridrato de clonidina & Não & Lidocaína + hidrocortisona + & Não \\
\hline Ácido policrílico & Não & Cloridrato de diltiazem & Não & subacetato de alumínio + & \\
\hline Adefovir dipivoxil & Não & Cloridrato de dorzolamida & Não & óxido de zinco & \\
\hline Aesculus hippocastanum & Não & Cloridrato de dorzolamida + & Não & Lorazepam & Não \\
\hline Alprazolam & Não & maleato de timolol & & Losartan & Não \\
\hline Amilorida + hidroclorotiazida & Não & Clortalidona & Não & Memantina & Não \\
\hline Aripripazol & Não & Cloxazolam & Não & Mesilato de imatinib & Não \\
\hline Baclofeno & Não & Colagenase & Não & Metilfenidato & Não \\
\hline Bamifilina & Não & Complexo B & Não & Metoclopramida + dimeticona & Não \\
\hline Benzoato de sódio & Não & Deflazacort & Não & + ácido desidrocólico & \\
\hline Betametasona + gentamicina & Não & Diacereína & Não & Milnaciprano & Não \\
\hline + tolnaftato + clioquinol & & Diidroergotoxina & Não & Mirtazapina & Não \\
\hline Bicalertamida & Não & Diosmina & Não & Monosialotetraesosilgangliosideo & Não \\
\hline Bisoprolol & Não & Diosmina + hesperidina & Não & Montelucaste sódico & Não \\
\hline Bosentana & Não & Doxazosina & Não & Mucopolissacaridase & Não \\
\hline Bromazepan & Não & Efalizumabe & Não & Nateglinida & Não \\
\hline Bromoprida & Não & Enoxaparina sódica & Não & Nimesulida & Não \\
\hline Bromoprida + celulase + & Não & Escina & Não & Nimodipino & Não \\
\hline dimeticona + pancreatina & & Estazolam & Não & Nistatina + óxido de zinco & Não \\
\hline Candesartan cilexetila & Não & Etinilestradiol + acetato de & Não & Olmesartana medoxomila & Não \\
\hline Capecitabina & Não & ciproterona & & Orlistat & Não \\
\hline Carbidopa + levodopa + & Não & Etoricoxib & Não & Oxcarbazepina & Não \\
\hline entacapona & & Extrato seco de Hedera helix & Não & Oxibutinina & Não \\
\hline Carbonato de cálcio + & Não & Ferro (quelato glicinato) & Não & Óxido de zinco & Não \\
\hline vitamina D & & Fexofenadina & Não & Palivizumab & Não \\
\hline Carboximetilcelulose sódica & Não & Fibrinolisina + cloranfenicol + & Não & Pancrease & Não \\
\hline Carisoprodol + dipirona + & Não & desoxirribonuclease & & Pantoprazol & Não \\
\hline vitamina $\mathrm{B} 1+$ vitamina $\mathrm{B} 6+$ & & Fluticasona & Não & Paracetamol + cafeína + & Não \\
\hline vitamina B12 & & Folitropina alfa & Não & carisopridol + diclofenaco & \\
\hline Carnitina & Não & Fosfatidilserina & Não & de sódio & \\
\hline Carvedilol & Não & Galantamina & Não & Paroxetina & Não \\
\hline Cassia angustiflia + & Não & Gangliosídeos & Não & Penfluridol & Não \\
\hline associações & & Ginkgo biloba & Não & Periciazina & Não \\
\hline Celecoxib & Não & Glimepirida & Não & Perindopril & Não \\
\hline Cetorolaco de trometamina & Não & Hidróxido de ferro & Não & Piribedil & Não \\
\hline Cilostazol & Não & (ferro polimaltosado) & & Plantago ovata forsk & Não \\
\hline Cinarizina & Não & Hidroxizina & Não & Poliestirenossulfonato de cálcio & Não \\
\hline Citalopram & Não & Hipromelose + dextrano $70+$ & Não & Propatilnitrato & Não \\
\hline Citidina + uridina + & Não & glicerol & & Rapamicina & Não \\
\hline hidroxocobalamina & & Hipromelose + dextrano $70+$ & Não & Repaglinida & Não \\
\hline Citrato de sódio & Não & poliquartenio-1 & & Resource glutamine & Não \\
\hline Clobazam & Não & Imipramina & Não & Resource protein & Não \\
\hline Clopidogrel & Não & Imiquimod & Não & Risedronato sódico & Não \\
\hline Cloranfenicol + colagenase & Não & Indapamida & Não & Rosuvastatina (cálcica) & Não \\
\hline Clordiazepoxido + cloridrato & Não & Ibesartana & Não & Rutina + castanha da Índia + & Não \\
\hline de amitriptilina & & Latanoprost & Não & extrato de miroton & \\
\hline
\end{tabular}

(continua) 
Tabela 1 (continuação)

\begin{tabular}{|c|c|c|c|c|c|}
\hline Produtos & Padronizado & Produtos & Padronizado & Produtos & Padronizado \\
\hline Salmeterol + fluticasona & Não & Ácido folínico & Sim & Clozapina & Sim \\
\hline Serenoa repens & Não & Ácido valpróico & $\operatorname{Sim}$ & Colchicina & $\operatorname{Sim}$ \\
\hline Sildenafil & Não & Adalimumabe & Sim & Dexametasona & Sim \\
\hline Sulfato de glicosamina & Não & Alendronato de sódio & Sim & Dexclorfeniramina & Sim \\
\hline Sulfato de glicosamina + & Não & Alopurinol & Sim & Diazepam & Sim \\
\hline sulfato de condroitina & & Amantadina & Sim & Diclofenaco sódico & Sim \\
\hline Sulfato de neomicina + & Não & Aminofilina & Sim & Digoxina & $\operatorname{Sim}$ \\
\hline bacitracina & & Amitriptilina & Sim & Dinitrato de isossorbida & Sim \\
\hline Sulfato ferroso + & Não & Amoxacilina & Sim & Dipirona & Sim \\
\hline ácido ascórbico + ácido fólico & & Amoxicilina + ácido clavulânico & Sim & Divalproato de sódio & Sim \\
\hline Sulfato ferroso + vitamina $\mathrm{C}+$ & Não & Anastrozol & Sim & Donepezila & Sim \\
\hline complexo B & & Atenolol & Sim & Dornase alfa & Sim \\
\hline Tadalafila & Não & Atorvastatina cálcica & Sim & Efavirenz & Sim \\
\hline Tamsulosina & Não & Azatioprina & Sim & Enalapril, maleato & Sim \\
\hline Tartarato de brimonidina & Não & Azitromicina diidratada & Sim & Enfuvirtida & Sim \\
\hline Temozolomida & Não & Beclometasona & Sim & Eritropoetina humana & Sim \\
\hline Tenoxicam & Não & Beclometasona + salbutamol & Sim & recombinante & \\
\hline Teriparatida & Não & Besilato de anlodipino & $\operatorname{Sim}$ & Espironolactona & Sim \\
\hline Tiamina + piridoxina + & Não & Bicarbonato de sódio & Sim & Estriol & Sim \\
\hline cianocobalamina & & Brometo de ipratrópio & Sim & Etambutol & Sim \\
\hline Ticlopidina & Não & Brometo de ipratrópio + & Sim & Etanercepte & Sim \\
\hline Tioridazina & Não & bromidrato de fenoterol & & Exemestano & Sim \\
\hline Travoprost & Não & Brometo de ipratrópio + & Sim & Fenitoína & Sim \\
\hline Tribenosido & Não & sulfato de salbutamol & & Fenobarbital & Sim \\
\hline Trientine & Não & Bromidrato de fenoterol & Sim & Fenofibrato & $\operatorname{Sim}$ \\
\hline Trifluoperazina & Não & Bromocriptina & Sim & Fludrocortisona & Sim \\
\hline Trifolium pratense L. & Não & Budesonida & Sim & Fluoxetina & Sim \\
\hline Trimetazidina & Não & Cabergolina & Sim & Formoterol & Sim \\
\hline Uréia & Não & Calcitonina & $\operatorname{Sim}$ & Fumarato de formoterol + & Sim \\
\hline Ursodiol & Não & Calcitriol & Sim & budesonida & \\
\hline Valeriana officinalis L. & Não & Captopril & Sim & Furosemida & Sim \\
\hline Valsartan & Não & Carbamazepina & Sim & Gabapentina & Sim \\
\hline Vitamina B12 & Não & Carbidopa + levodopa & Sim & Glatiramer & Sim \\
\hline Vitamina D & Não & Carbonato de cálcio & Sim & Glibenclamida & Sim \\
\hline Vitamina $\mathrm{E}$ & Não & Carbonato de lítio & Sim & Gliclazida & Sim \\
\hline Vitaminas (complexo & Não & Cefalexina monoidratada & Sim & Haloperidol & Sim \\
\hline multivitamínico) & & Ciclosporina & $\operatorname{Sim}$ & Hidralazina & $\operatorname{Sim}$ \\
\hline Vitaminas A + D & Não & Ciprofibrato & Sim & Hidroclorotiazida & Sim \\
\hline Vitaminas B12, D2 + & Não & Ciprofloxacina & Sim & Hidroxicloroquina & Sim \\
\hline fosfato de cálcio & & Ciproterona & $\operatorname{Sim}$ & Hidróxido de ferro (endovenoso) & Sim \\
\hline Acetato de ciproterona & Sim & Citrato de tamoxifeno & Sim & Hidróxido de magnésio & Sim \\
\hline Acetato de desmopressina & Sim & Clonazepam & Sim & Imunoglobulina & Sim \\
\hline Acetato de glatiramer & Sim & Cloreto de potássio & Sim & Infliximabe & Sim \\
\hline Acetato de gosserrelina & Sim & Cloridrato de alfuzosina & Sim & Insulina humana regular & Sim \\
\hline Acetato de leuprolida & Sim & Cloridrato de amiodarona & Sim & Interferon alfa-2B & Sim \\
\hline Acetato de leuprorrelina & Sim & Cloridrato de amitriptilina & Sim & Interferon beta & Sim \\
\hline Acetato de megestrol & Sim & Cloridrato de biperideno & Sim & Interferon beta-1A & Sim \\
\hline Acetato de octreotida & Sim & Cloridrato de bupropiona & Sim & Idopovidona & Sim \\
\hline Acetilcisteína & Sim & Cloridrato de clomipramina & Sim & lotretinoína & Sim \\
\hline Aciclovir & $\operatorname{Sim}$ & Cloridrato de clorpromazina & $\operatorname{Sim}$ & Itraconazol & $\operatorname{Sim}$ \\
\hline Ácido acetilsalicílico & Sim & Cloridrato de donepezil & Sim & Lactulose & Sim \\
\hline Ácido ascórbico & Sim & Cloridrato de piridoxina & $\operatorname{Sim}$ & Lamivudina & $\operatorname{Sim}$ \\
\hline Ácido fólico & $\operatorname{Sim}$ & Cloroquina & Sim & Leflunomide & Sim \\
\hline
\end{tabular}

(continua) 
Tabela 1 (continuação)

\begin{tabular}{|c|c|c|c|c|c|}
\hline Produtos & Padronizado & Produtos & Padronizado & Produtos & Padronizado \\
\hline Levodopa + cloridrato de & Sim & Penicilamina & Sim & Sinvastatina & Sim \\
\hline benserazida & & Pentoxifilina & Sim & Somatropina & Sim \\
\hline Levotiroxina sódica & Sim & Piridostigmina & Sim & Somatrotofina & Sim \\
\hline Loratadina & Sim & Pirimetamina & Sim & Soro fisiológico & Sim \\
\hline Maleato de timolol & Sim & Pramipexol & Sim & Sulfadiazina de prata & Sim \\
\hline Mesalazina & Sim & Pravastatina & Sim & Sulfato ferroso & Sim \\
\hline Metformina & Sim & Pravastatina sódica & Sim & Tacrolimus & Sim \\
\hline Metoclopramida & Sim & Prednisona & Sim & Tenofovir & Sim \\
\hline Metotrexato & Sim & Prometazina & Sim & Teofilina & Sim \\
\hline Micofenolato mofetil & Sim & Propranolol & Sim & Topiramato & Sim \\
\hline Mononitrato de isossorbida & Sim & Quetiapina & Sim & Toxina botulínica tipo A & Sim \\
\hline Neomicina & Sim & Raloxifeno & Sim & Triexifenidila & Sim \\
\hline Nifedipino & Sim & Ranitidina & Sim & Trimetoprima + sulfametoxazol & Sim \\
\hline Nitrofurantoína & Sim & Ribavirina & Sim & Tropicamida & Sim \\
\hline Nortriptilina & Sim & Riluzol & Sim & Valerato de betametasona & Sim \\
\hline Olanzapina & Sim & Risperidona & Sim & Varfarina sódica & Sim \\
\hline Omeprazol & Sim & Rivastigmina & Sim & Verapamil & Sim \\
\hline Omeprazol + claritromicina + & Sim & Salbutamol & Sim & Vigabatrina & Sim \\
\hline amoxicilina & & Selegilina & Sim & Zidovudina & Sim \\
\hline Pancrelipase & Sim & Sevelamer (hidrocloreto & Sim & Ziprasidona & Sim \\
\hline Paracetamol & Sim & de sevelamer) & & & \\
\hline Paracetamol + codeína & Sim & & & & \\
\hline
\end{tabular}

o fornecimento de medicamentos, uma vez que tais normas possuem caráter geral e não têm o escopo de definir o exato conteúdo do direito à saúde. No caso dos medicamentos, essa delimitação está prevista em atos administrativos emanados do Ministério da Saúde, especialmente na RENAME, em Portarias e em programas específicos de assistência farmacêutica, que definem os produtos disponibilizados pela assistência farmacêutica no país. Assim sendo, são esses últimos documentos que devem servir de critério ao Poder Judiciário para decidir sobre o fornecimento de medicamentos.

Aliás, já é possível observar a utilização da seleção oficial em matéria de medicamentos como fundamento de algumas decisões judiciais. No Superior Tribunal de Justiça, decisão recente da Ministra Eliana Calmon atentou para a questão da padronização, destacando que o dever do Estado garantir o direito à vida e à saúde não se confunde com o direito de escolha do paciente a medicamentos específicos 20 . No mesmo sentido, o Supremo Tribunal Federal, por meio de decisão da Ministra Ellen Gracie 21, suspendeu liminar concedida por juiz de primeira instância em ação civil pública que tinha por objeto a determinação genérica de que o Estado fornecesse "todo e qualquer medicamento necessário ao tratamento dos transplantados renais e pacientes renais crônicos". A decisão considerou a questão da padronização, decidindo que ao Estado compete fornecer tão somente os medicamentos contemplados na portaria que regulamenta os medicamentos excepcionais.

As mencionadas decisões indicam que o Poder Judiciário começa a reconhecer a importância da seleção oficial de medicamentos como condição para viabilidade da assistência farmacêutica no SUS. Entretanto, os processos que chegam aos tribunais superiores são poucos se comparados aos que são decididos diariamente pelos juízes de primeira instância, que, como mostram os dados, ainda não consideram tal seleção como fundamento de suas decisões.

Portanto, o já referido novo formato de judicialização da política, caracterizado por uma busca individualizada para efetivação do direito à saúde e por uma atuação do Poder Judiciário, especialmente dos juízes de primeira instância, desvinculada das políticas e da regulamentação pensadas pelo Poder Executivo, poderá gerar desequilíbrios à assistência farmacêutica no SUS, inviabilizando o planejamento de políticas públicas, porquanto os medicamentos dispensados nem sempre são os tecnicamente adequados, sendo certo ainda que as despesas com itens não 
previstos na política de medicamentos tornam incontornável a divisão e alocação eqüitativa de recursos finitos no sistema.

Além de desorganizarem o sistema 22, algumas decisões representam verdadeira violação ao princípio da isonomia, previsto no Artigo 5o, caput, da Constituição Federal, uma vez que o fornecimento de determinado medicamento não padronizado para um indivíduo pode representar a falta de outros para o restante da coletividade, contribuindo, desta forma, para acentuar as iniqüidades dentro do sistema de saúde 23 . Acrescente-se ainda que a dispensação de medicamentos pelo Poder Judiciário sem observância da seleção oficial pode comprometer outras diretrizes da Política Nacional de Medicamentos estabelecidas na Portaria $n^{\circ}$. 3.916/98, tal como a promoção do uso racional de medicamentos, já que a prescrição nem sempre é adequada às necessidades de saúde do indivíduo ou ainda este pode não se enquadrar nos critérios dos Protocolos Clínicos e Diretrizes Terapêuticas do Ministério da Saúde.

Por outro lado, se por parte do Poder Judiciário se observa um excesso de intervenção na questão do fornecimento de medicamentos, uma vez que as decisões judiciais geralmente não são tomadas com base em informações técnico-científicas, por parte do Poder Executivo - e dos respectivos órgãos de saúde em cada nível de governo responsáveis pela dispensação de medicamentos - se observa uma postura omissiva, pois nada menos que $52 \%$ dos medicamentos pleiteados nas ações judiciais se referem a produtos incluídos na regulamentação farmacêutica no âmbito do SUS.

Essa situação indica que os autores dessas ações judiciais tiveram de acessar o Poder Judiciário para obter o fornecimento de determinado medicamento que deveria lhes ter sido dispensado pelo Poder Executivo, por meio do competente órgão de saúde. Nesse caso, se vislumbram duas hipóteses distintas: a do indivíduo que primeiramente recorreu ao órgão de saúde e teve o fornecimento do medicamento negado, buscando então a via do Poder Judiciário; e a daquele que sequer tentou receber o medicamento por intermédio do órgão de saúde competente, e de posse da respectiva prescrição recorreu diretamente ao Poder Judiciário para obter o seu fornecimento.

Apesar de a análise dos fatos que antecedem a busca ao Poder Judiciário não fazer parte desta pesquisa, é importante destacar as duas hipóteses mencionadas, pois como o indivíduo não necessita comprovar na via judicial que tentou receber anteriormente o medicamento por meio do competente órgão de saúde, a sua opção em recorrer ao Poder Judiciário pode estar relacionada não somente à recusa no fornecimento do medicamento pela administração pública, mas também ao tempo de espera que o órgão de saúde possa impor para fornecê-lo, neste caso provavelmente mais longo do que o tempo imposto para obtenção do medicamento pela via judicial.

Observa-se, portanto, que, seja pela negativa em fornecer o medicamento ou pelo tempo imposto ao indivíduo, os órgãos do Poder Executivo têm falhado na prestação da assistência farmacêutica, especialmente na dispensação de medicamentos, que tem sido resolvida nesses casos pela busca ao Poder Judiciário. A omissão do Poder Executivo fica mais clara quando se constata que mesmo depois de propostas as ações judiciais - e sabendo-se que $52 \%$ dos medicamentos pleiteados estão em listas ou programas oficiais - apenas em $1 \%$ dos processos houve o reconhecimento por parte da administração pública de que o medicamento era devido.

Nesse sentido, não se pode ignorar que $34,5 \%$ dos custos em saúde são constituídos pelos gastos diretos das famílias na compra de bens e serviços de saúde. Desses, a maior parte é causada pelo gasto em medicamentos, que afeta preponderantemente a população mais pobre: a despesa com medicamentos representa nada menos que $82 \%$ do custo direto em saúde efetuado pelo decil mais pobre da população brasileira e se constitui, em todos os decis, o mais importante item de gasto privado direto da nossa sociedade 24 .

O problema do acesso gratuito aos medicamentos constitui-se, portanto, em uma das principais questões pendentes no SUS. Na esfera judicial o tema tornou-se igualmente relevante devido ao elevado número de ações judiciais visando ao fornecimento de medicamentos. Prova disso foi a audiência pública realizada pelo Supremo Tribunal Federal nos dias 27, 28 e 29 de abril e 4, 6 e 7 de maio de 2009, a fim de que membros da sociedade, entre advogados, defensores públicos, promotores e procuradores de justiça, magistrados, professores, médicos, técnicos de saúde, gestores e usuários do SUS discutissem o tema diretamente com o Poder Judiciário 25 .

Vislumbra-se, assim, uma espécie de "queda de braço" entre o Poder Executivo e o Poder Judiciário no que se refere ao fornecimento de medicamentos, na qual este último visando a suprir as omissões daquele Poder passou a deferir todos os pedidos formulados nas ações judiciais. De fato, um dos papéis do Poder Judiciário é o de suprir as omissões ou controlar os abusos praticados pelos demais Poderes, devendo cuidar apenas para que no seu atuar também não venha a extrapolar limites. Na questão do fornecimento 
de medicamentos, o Poder Judiciário deve continuar cumprindo o seu papel de intervir nos casos em que o Poder Executivo indevidamente se omitiu, garantindo assim o acesso da população a medicamentos e efetivando o direito à saúde. E como confirmam os dados, a atuação do Poder Judiciário tem se mostrado necessária, já que mais da metade dos medicamentos pleiteados fazem parte da regulamentação da assistência farmacêutica no âmbito do SUS e deveriam, portanto, ter sido previamente fornecidos na esfera executiva.

Todavia, para que o Poder Judiciário não transforme sua atuação em excessiva intervenção na política de assistência farmacêutica, desorganizando o sistema, deve observar a regulamentação farmacêutica no âmbito do SUS, que, como já antes mencionado, são normas técnicas, incluindo a RENAME, Portarias e programas de assistência farmacêutica. Destaque-se que a observação da regulamentação da assistência farmacêutica por parte do Poder Judiciário, por si só, já representa uma opção que incorpora uma série de outros critérios, pois o Poder Executivo ao promover a seleção de medicamentos utiliza variados critérios, tais como custo/benefício, dose/efetividade, risco/benefício e efetividade/ eficácia 26 .

Nos casos em que os medicamentos pleiteados não estiverem previstos na regulamentação sobre a matéria, o Poder Judiciário deverá, então, cogitar de outros critérios para decidir. Assim, deverão ser observados fatores como a indispensabilidade do medicamento para a manutenção da vida do indivíduo, e, adicionalmente, a opção pelo medicamento nacional, e, ainda, se possível, a opção pelo medicamento genérico, de menor custo e eficácia comprovada 27 .

Outro fator a ser observado e utilizado como critério pelo Poder Judiciário é verificar se o médico prescritor do medicamento, e desta forma o receituário constante do processo judicial, pertence ao SUS, de maneira a não se inverter a lógica do sistema, privilegiando-se a compra de medicamentos a pacientes que não utiliza- ram as portas de entrada do SUS. Ressalte-se que existem evidências de que o gasto público decorrente das demandas judiciais por medicamentos é altamente regressivo, uma vez que favorece os segmentos de mais alta renda da população, pois grande parte das prescrições nos processos judiciais é proveniente dos serviços privados de saúde 28 . Tal critério justifica-se também devido à forte pressão exercida pela indústria farmacêutica sobre os médicos 29 , principalmente sobre aqueles que trabalham em consultórios, por receberem com freqüência propagandas de medicamentos distribuídas pelos visitadores de indústrias farmacêuticas, as quais, em sua grande parte, trazem informações pouco confiáveis, privilegiando benefícios em detrimento de riscos e omitindo ou alterando dados importantes sobre os fármacos 30 .

Conclui-se, assim, que apesar de não ser o Poder Judiciário a esfera adequada para a solução de conflitos envolvendo o fornecimento de medicamentos, o fato é que cada vez mais este tipo de conflito é levado à apreciação deste Poder. Portanto, para que o Poder Judiciário lide adequadamente com o fenômeno, sem intervir excessivamente nas políticas de saúde, deve tratar o tema com a devida precaução, respaldando suas decisões em critérios - tal como anteriormente exposto - que vão além da simples fundamentação no dispositivo constitucional e na $L e i$ $n^{\circ}$. 8.080/90.

Finalmente, é importante ressaltar que, ainda que a via judicial não seja a forma adequada para o fornecimento de medicamentos à população, o crescimento das demandas judiciais para este fim indica uma difusão e absorção dos direitos e princípios constitucionais pela sociedade e uma facilitação do acesso à justiça no país. Além disso, as demandas judiciais podem operar um efeito indutor no processo político, não só alterando as políticas públicas já em curso, mas indicando como devem ser pensadas as políticas para o futuro, e neste caso serve o Poder Judiciário também como veículo a ampliar a dimensão dos conflitos sociais em curso 31 . 


\section{Resumo}

Partindo-se de uma análise das ações judiciais individuais para o fornecimento de medicamentos propostas por usuários do Sistema Único de Saúde (SUS) contra o Estado do Rio de Janeiro, Brasil, no ano de 2005, este estudo tem como objetivo discutir a atuação e o comportamento do Poder Judiciário no julgamento dos referidos processos judiciais. O estudo corresponde a uma pesquisa documental exploratória, de caráter quali-quantitativo, na qual foram analisados alguns aspectos relacionados às ações judiciais, tais como, o tipo de medicamento pleiteado, o teor das decisões proferidas e os fundamentos mais freqüentes utilizados pelos magistrados no julgamento das ações. Com base no resultado da análise das ações, do conceito de judicialização e da padronização oficial em matéria de medicamentos, concluiu-se que, ao decidir sobre o fornecimento de medicamentos, o Poder Judiciário concede os pedidos formulados sem considerar a padronização de medicamentos adotada pelo Ministério da Saúde, exercendo assim uma excessiva intervenção na política de saúde.

Preparações Farmacêuticas; Poder Judiciário; Política de Saúde; Sistema Único de Saúde

\section{Colaboradores}

D. C. L. Borges contribuiu na pesquisa e redação do artigo. M. A. D. Ugá colaborou na concepção, determinação da metodologia e revisão do artigo.

\section{Referências}

1. Messeder AM, Osorio-de-Castro CGS, Luiza VL. Mandados judiciais como ferramentas para garantia do acesso a medicamentos no setor público: a experiência do Estado do Rio de Janeiro, Brasil. Cad Saúde Pública 2005; 21:525-34.

2. Amaral G. Direito, escassez e escolha: em busca de critérios jurídicos para lidar com a escassez de recursos e as decisões trágicas. Rio de Janeiro: Editora Renovar; 2001.

3. Vianna LW, Carvalho MAR, Melo MPC, Burgos MB. A judicialização da política e das relações sociais no Brasil. Rio de Janeiro: Editora Revan; 1999.

4. Maciel DA, Koerner A. Sentidos da judicialização da política: duas análises. Lua Nova: Revista de Cultura e Política 2002; (57):113-33.
5. Ferreira CD, Oliveira AAC, Machado AMF, Nahoum AV, Ferrão BLM, Cardoso ELC, et al. O judiciário e as políticas de saúde no Brasil: o caso AIDS http://getinternet.ipea.gov.br/SobreIpea/40anos/ estudantes/monografiacamila.doc (acessado em 20/Jan/2009).

6. Lopes JRL. Direitos sociais: teoria e prática. São Paulo: Editora Método; 2006.

7. Ferraz OLM, Vieira FS. Direito à saúde, recursos escassos e equidade: os riscos da interpretação judicial dominante. Dados Rev Ciênc Sociais 2009; 52:223-51.

8. Brasil. Portaria $n^{\circ}$. 3.916/GM de 30 de novembro de 1998. Aprova a Política Nacional de Medicamentos. Diário Oficial da União 1998; 10 dez. 
9. Santos L. SUS: contornos jurídicos da integralidade da atenção à saúde. Radis Comunicação em Saúde 2006; (49). http://www.ensp.fiocruz.br/ radis/49/web-02.html.

10. Pepe VLE. A Relação Nacional de Medicamentos Essenciais (RENAME): a seleção de medicamentos noBrasil.http://www.ensp.fiocruz.br/portal-ensp/ judicializacao/pdfs/340.pdf (acessado em 10/ Ago/2009).

11. Pontes Junior DM. A seleção de medicamentos para o monitoramento da qualidade laboratorial no Brasil: articulação entre a vigilância sanitária e a Política Nacional de Medicamentos [Dissertação de Mestrado]. Rio de Janeiro: Escola Nacional de Saúde Pública, Fundação Oswaldo Cruz; 2007.

12. Gerência Técnica de Assistência Farmacêutica, Secretaria de Políticas de Saúde, Ministério da Saúde. Relação Nacional de Medicamentos Essenciais: RENAME. 3a Ed. Brasília: Ministério da Saúde; 2002. (Série B. Textos Básicos de Saúde).

13. Marques SB, Dallari SG. Garantia do direito social à assistência farmacêutica no Estado de São Paulo. Rev Saúde Pública 2007; 41:101-7.

14. Tribunal de Justiça do Estado do Rio de Janeiro. Súmula TJ $n^{\circ}$. 65. Diário Oficial do Estado do Rio de Janeiro 2003; 23 set.

15. Conselho Nacional de Secretários de Saúde. Assistência farmacêutica no SUS. 1ạ Ed. Brasília: Conselho Nacional de Secretários de Saúde; 2007. (Coleção Progestores, 7).

16. Biehl J, Petryna A, Gertner A, Amon JJ, Picon PD. Judicialisation of the right to health in Brazil. Lancet 2009; 373:2182-4.

17. Schwartz G. Direito à saúde: efetivação em uma perspectiva sistêmica. Porto Alegre: Livraria do Advogado Editora; 2001.

18. Gouvêa MM. O controle judicial das omissões administrativas. Rio de Janeiro: Editora Forense; 2003.

19. Torres RL. A cidadania multidimensional na era dos direitos. In: Torres RL, organizador. Teoria dos direitos fundamentais. 2a Ed. Rio de Janeiro: Editora Renovar; 2001. p. 243-342.

20. Brasil. Recurso em mandado de segurança $n^{\circ}$. 28.338 - MG (2008/0264294-1). Diário Oficial da União 2009; 27 jun.
21. Brasil. Suspensão de tutela antecipada no. 91. Diário Oficial da União 2007; 5 mar.

22. Gouvêa MM. O Direito ao fornecimento estatal de medicamentos. Revista de Direito da Associação dos Procuradores do Novo Estado do Rio de Janeiro 2003 ; 12:119-65.

23. Ferraz OLM. The right to health in the courts of Brazil: worsening health inequities? Health Hum Rights; no prelo.

24. Ugá MAD, Santos IS. Uma análise da progressividade do financiamento do Sistema Único de Saúde (SUS). Cad Saúde Pública 2006; 22:1597-609.

25. Supremo Tribunal Federal. Audiência pública saúde. http://www.stf.jus.br/portal/cms/verTexto. asp? servico=processoAudienciaPublicaSaude (acessado em 13/Ago/2009).

26. Fernandes AMMS, Osorio-de-Castro CGS, Luiza VL. Arcabouço legal da política nacional de medicamentos no Brasil: uma revisão. In: Garcia M, Pepe VLE, Andrade CR, Pontes Junior DM, organizadores. Vigilância em saúde. v. 1. Rio de Janeiro: Escola Nacional de Saúde Pública, Fundação Oswaldo Cruz; 2004. p. 13-41. (Coleção Escola de Governo em Saúde. Série Trabalhos de Alunos).

27. Barroso LR. Da falta de efetividade à judicialização excessiva: direito à saúde, fornecimento gratuito de medicamentos e parâmetros para a atuação judicial. http://conjur.estadao.com.br/pdf/ estudobarroso.pdf (acessado em 22/Jan/2009).

28. Pereira JR, Santos RI, Nascimento Junior JM, Schenkel EP. Análise das demandas judiciais para o fornecimento de medicamentos pela Secretaria de Estado da Saúde de Santa Catarina nos anos de 2003 e 2004. Ciênc Saúde Coletiva; no prelo.

29. Temporão JG. A propaganda de medicamentos e o mito da saúde. São Paulo: Edições Graal; 1986.

30. Veira RCPA. Propagandas de Medicamentos distribuídas aos médicos: aspectos legais, farmacológicos e de mercadização [Tese de Doutorado]. Rio de Janeiro: Instituto de Medicina Social, Universidade do Estado do Rio de Janeiro; 2004.

31. Stone-Sweet A. Governing with judges: constitutional politics in Europe. Oxford: Oxford University Press; 2000 .

Recebido em 20/Mar/2009

Versão final reapresentada em 31/Ago/2009

Aprovado em 21/Out/2009 